\title{
Influence of Prototropic Reactions on the Absorption and Fluorescence Spectra of Methyl p-dimethylaminobenzoate and Its Two Ortho Derivatives
}

\author{
M. Józefowicz • M. Aleksiejew • A. V. Abramov • \\ S. Ling • M. Gutowski $\cdot$ J. Heldt • J. R. Heldt
}

Received: 22 December 2010 / Accepted: 17 February 2011/Published online: 5 March 2011

(C) The Author(s) 2011. This article is published with open access at Springerlink.com

\begin{abstract}
The influence of prototropic reactions on the spectral characteristics of methyl p-dimethylaminobenzoate (I) and its o-methoxy (II) and o-hydroxy (III) derivatives has been studied using steady-state spectroscopic technique and quantum-chemical calculations. This study concerns the solvent-induced shift of the absorption, locally excited (LE) and intramolecular charge transfer (ICT) fluorescence bands in the neat tetrahydrofuran (THF) and its hydrochloric acid solutions at different $\mathrm{HCl}$ concentrations. On the basis of the experimental results and quantum-chemical calculations, it was shown that in a hydrochloric acid solution the studied molecules exist as a mixture of neutral, mono-, and dicationic forms. Additionally, the results of spectroscopic measurements were used to calculate, according to the Benesi-Hildebrand method, the equilibrium constants of protopropic reactions in the ground, $S_{0}$, and excited, $S_{1}$, states. Our findings predestine molecules I and II to be used as acid fluorescence probes in a region of 0 $2.5 \mathrm{M}$ of $\left[\mathrm{H}^{+}\right]$concentrations.
\end{abstract}

Keywords Methyl p-dimethylaminobenzoate · Absorption and emission spectra $\cdot$ Quantum-chemical calculations . Fluorescence quenching

Dedicated to Professor Michael Kasha on the occasion of his 90-th birthday

M. Józefowicz $(\varangle) \cdot$ M. Aleksiejew $\cdot$ J. Heldt $\cdot$ J. R. Heldt Institute of Experimental Physics, University of Gdańsk, ul. Wita Stwosza 57, 80-952 Gdańsk, Poland

e-mail: fizmj@univ.gda.pl

A. V. Abramov $\cdot$ S. Ling $\cdot$ M. Gutowski

Department of Chemistry, School of Engineering and Physical Sciences, Heriot-Watt University,

Edinburgh EH14 4AS, UK

\section{Introduction}

In a series of papers [1-10], it has been shown that methyl pdimethylaminobenzoate (I) and its ortho derivatives $\left(-\mathrm{OCH}_{3}\right.$ (II) and $-\mathrm{OH}$ (III)) exhibit dual fluorescence in polar solvents, i.e., the normal (locally excited (LE)) fluorescence $S_{1}(L E) \rightarrow S_{0}(L E)$ and the twisted intramolecular charge transfer fluorescence $S_{1}(I C T) \rightarrow S_{0}$ (ICT). The two emission modes originate from independent electronic transitions of planar and non-planar spatial conformers, in which the plane of the electron donor substituent $\left(-\mathrm{NMe}_{2}\right)$ is parallel or perpendicular to the plane of benzene skeleton. In polar solvents, the initially populated LE state reacts further to produce a stable twisted intramolecular charge transfer (TICT) state, which gives rise to a second (long-wavelength) fluorescence band. This conformation change facilitates an electron transfer process from the donor $\left(-\mathrm{NMe}_{2}\right)$ to the methyl benzoate skeleton (charge accepting moiety). The appearance of two or three radiative modes in the fluorescence spectrum, associated with a definite isomeric or tautomeric form of the excited molecule, has been confirmed by picosecond transient absorption measurements [3] and steady-state absorption and fluorescence studies [1, 2, 4-9] in solvents of different polarity.

The isomeric or tautomeric spatial form of the parent molecule possesses a higher electric dipole moment and emits fluorescence quanta of lower energy. Its photophysical parameters, e.g., transition energy $E_{00}$, fluorescence rate constant $k_{F}=Q_{F} / \tau_{F}$ (fluorescence quantum yield $Q_{F}$ and lifetime $\tau_{F}$ ) differ significantly from that of the parent molecule $[2,4,8,9]$. The efficiencies of the photoinduced intramolecular reactions i.e., the intramolecular charge transfer $S_{1}(L E) \rightarrow S_{1}(I C T)$ or the intramolecular proton transfer $S_{1}(L E) \rightarrow S_{1}(I P T)$ are determined by the dipoledipole solute-solvent interactions, as well as they can be 
influenced by external factors such as a short range anisotropic interaction (hydrogen bonding) with one or more solvent molecules causing changes in the absorption and fluorescence spectra (changes in fluorescence yield, the shape of fluorescence emission spectra, position of fluorescence maxima) [10]. Ghosh and co-workers [11] have shown that a chemical reaction of a $\mathrm{H}^{+}$ion with the $-\mathrm{NMe}_{2}$ substitutent changes the $\mathrm{C}-\mathrm{N}$ bond length and as a consequence makes torsional motions to be more complex. As a result of that the dialkylamino group forms a specific complex, which severely polarises one end of the molecule.

Since our earlier papers [7,8] concern spectroscopic studies of methyl p-dimethylaminobenzoate and its ortho derivatives, it is very interesting to study the influence of the $\mathrm{H}^{+}$ion concentration on the steady-state absorption and fluorescence spectra of methyl p-dimethylaminobenzoate (I) and its o-methoxy (II), o-hydroxy (III) derivatives. The chemical structures of compounds of interest are given in Scheme 1. The results of spectroscopic studies were compared with results of our quantum-chemical calculations.

\section{Methods}

Steady-state absorption and fluorescence measurements at room temperature were carried out using a computercontrolled Shimadzu UV-2401 PC Spectrophotometer and Shimadzu RF-5301 PC spectrofluorometer with a $3 \mathrm{~nm}$ bandwidth in excitation and $5 \mathrm{~nm}$ bandwidth in emission. Fluorescence measurements were carried out using the triangular cuvette with frontal excitation to minimize the effect of reabsorption. The emission was observed perpendicular to the direction of the exciting beam. Thus the errors due to fluorescence reabsorption were reduced in a way that mathematical corrections were superfluous. The luminescence spectra have been corrected for the spectral response of the photomultiplier Hamamatsu R-928. In the conversion between wavelength and wavenumber representation of the absorption and emission spectra the reweighing intensities factor has been taken into account [12].

The solvents tetrahydrofuran (THF) and hydrochloric acid $(\mathrm{HCl})$ were purchased from Aldrich Chemical Co as highest grade commercially available. Additionally, solvents were checked in both steady-state and time-resolved fluorescence apparatuses for lack of fluorescent impurities in the wavelength ranges of interest. The concentration of molecules in the solutions was about $10^{-4} \mathrm{M}$.

All calculations concerning absorption spectra of neutral and protonated molecules (see Scheme 1) were performed using the Gaussian 09 code [13]. The first problem that we addressed was identification of the most stable conformers. We used the Systematic Screening of Conformers (SSC) software $[14,15]$ to generate a library of conformers for each molecule. For the first four molecules (I, IA-B, and II) all rotational degrees of freedom were considered at this stage. Next, we recognized that the contribution from methyl groups to the overall stability of molecules is relatively small and can be decoupled from contributions associated with other rotational degrees of freedom. Thus for the remaining five molecules (IIA-B, III, IIIA-B) the rotational degrees of freedom of methyl groups were not considered when creating initial libraries of conformers with SSC. The stability of each conformer was initially determined in the course of geometry optimization with the B3LYP exchangecorrelation functional $[16,17]$ and the $6-31 \mathrm{G}^{*}$ basis set $[18]$, including geometrical relaxation of all methyl groups. A typical library created with SSC contained a few hundreds of conformers and the B3LYP/6-31G* optimization led to a few tens of distinct local minima, see Table 1 . For these local minima all meaningful conformers derived from rotations of methyl groups were considered. At the second stage, the structures of the most stable conformers of each molecule were further refined at the B3LYP/6-311G** level [19]. The number $n$ of conformers included at the second stage of search was selected in this way that the $(n+1)$-th conformer was less stable than the $n$-th conformer by at least $2 \mathrm{kcal} / \mathrm{mol}$. The details of our two-step procedure are summarized in Table 1. For example, for the diprotonated methyl o-hydroxy p-dimethylaminobenzoate (IIIB) the SSC software created 218 initial conformers and the B3LYP/6-31G* prescreening step led to 30 distinct conformers. The two most stable conformers spanned a narrow range of $0.2 \mathrm{kcal} / \mathrm{mol}$ and the third conformer was less stable by $7.6 \mathrm{kcal} / \mathrm{mol}$. Hence, only the first two conformers were considered at the second stage of optimization. The effect of solvation with THF was studied by performing additional optimizations within the polarized continuum model $(\varepsilon=7.58)$ [20] at the B3LYP/6-311G** level. Excited singlet electronic states for the most stable conformers were calculated using the time-dependent B3LYP/6-311G** method [21], with the effect of THF included by using the PCM model.

\section{Results and Discussion}

Absorption Spectra and Their Analysis on the Base of the Quantum-chemical Calculations

Figure 1(a, b, c) shows the absorption spectra of I, II and III in neat THF and its hydrochloric acid solutions at different $\mathrm{HCl}$ concentrations (from 0.098 to $6.065 \mathrm{M}$ ) keeping a constant solute concentration of $10^{-4} \mathrm{M}$. The absorption spectra, as it is seen in Fig. 1a, b and c, possess two bands: the long-wavelength band in the region of $260-340 \mathrm{~nm}$ and the short-wavelength band in the $210-260 \mathrm{~nm}$ region. In our paper the bands are signed as $\mathrm{C}$ and $\mathrm{B}$, respectively. In 
Methyl p-dimethylaminobenzoate<smiles>COC(=O)c1ccccc1N(C)C</smiles>

(I)

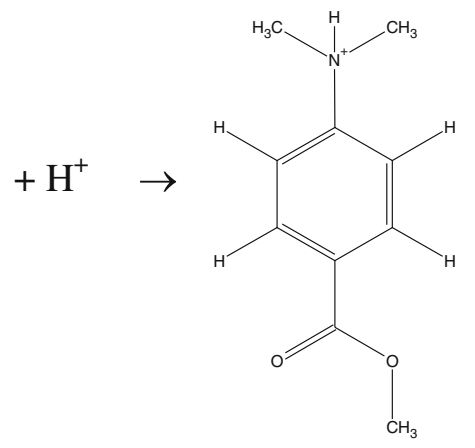

(IA)<smiles>COC(=O)c1cc([N+](C)(C)C)c(C)c(C)c1C</smiles>

(IB)

Methyl o-methoxy p-dimethylaminobenzoate<smiles>COC(=O)c1cc(I)c(N(C)C)c(I)c1O</smiles>

(II)

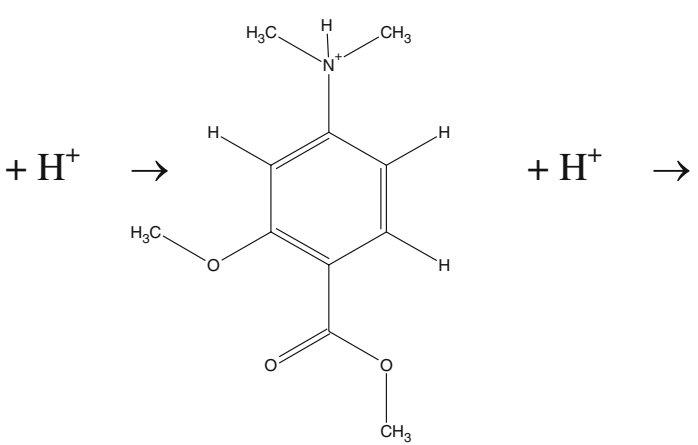

(IIA)<smiles>COC(=O)c1c(C)c(C)c(N(C)O)c(C)c1OC</smiles>

(IIB)

Methyl o-hydroxy p-dimethylaminobenzoate<smiles>COC(=O)c1cc(O)c(N(C)C)c(C)c1C</smiles>

(III)<smiles>COC(=O)c1cc(I)c(N(C)C)c(C)c1O</smiles>

(IIIA)<smiles>COC(=O)c1c(O)c(C)c([N+](C)(C)C)c(C)c1O</smiles>

(IIIB)

Scheme 1 Structures of methyl p-dimethylaminobenzoate and its o-methoxy and o-hydroxy derivatives (first column) and their monoprotonated (second column) and diprotonated (third column) forms

order to clarify the folded structure noted in the absorption spectrum of the molecules I, II and III, in our previous study we performed quantum-chemical calculations on these systems in vapour-phase [8]. From these calculations, it is evident that the long-wavelength absorption band in vapour-phase consists of two overlapping components (see
Fig. 1 and Table 2). It has been shown [7, 8] that the calculated $S_{0} \rightarrow S_{1}$ transition in the studied compounds is described by the same linear combination of HOMO and LUMO one electron $\pi$-orbital transitions (only with different composition) as the $S_{0}\left({ }^{1} A\right) \rightarrow S_{1}\left({ }^{1} L_{b}\right)$ band of benzene and MB (methyl benzoate). Additionally, the strong 
Table 1 Number of optimized structures and local minima for each step of conformation searches

\begin{tabular}{lccccc}
\hline \multirow{2}{*}{ Structure } & \multicolumn{2}{l}{ First step $\left(\mathrm{B} 3 \mathrm{LYP} / 6-31 \mathrm{G}^{*}\right)$} & & \multicolumn{2}{l}{ Second step (B3LYP/6-311G**) } \\
\cline { 2 - 3 } \cline { 5 - 6 } & Optimized structures & Local minima & & Optimized structures & Local minima \\
\hline I & 432 & 8 & & 7 & 1 \\
IA & 432 & 12 & & 4 & 2 \\
IB & 864 & 15 & & 11 & 6 \\
II & 2592 & 27 & & 6 & 3 \\
IIA & 179 & 17 & & 9 & 2 \\
IIB & 329 & 20 & & 2 & 2 \\
III & 116 & 12 & & 4 & 2 \\
IIIA & 112 & 16 & & 5 & 2 \\
IIIB & 218 & 30 & & 2 & 2 \\
\hline
\end{tabular}

peak located at $211 \mathrm{~nm}\left(47,400 \mathrm{~cm}^{-1}\right)$ for II and at $215 \mathrm{~nm}$ $\left(46,500 \mathrm{~cm}^{-1}\right)$ for III (see Fig. 1b and c) corresponds to the allowed transitions of benzene $\left(S_{0}\left({ }^{1} A\right) \rightarrow S_{1}\left({ }^{1} B_{b}\right)\right.$, signed by us as A band) at $\nu \cong 54,000 \mathrm{~cm}^{-1}$.

Here we would like to note that for all studied molecules in vapour-phase the longer wavelength transition possesses weaker intensity than that of the shorter wavelength (see Fig. 1 and Table 2). Its relative intensities $\left(I_{S_{2}}^{a b s} / I_{S_{1}}^{a b s}\right)$ depend on the molecules and equal 37 (for I), 8 (for II) and 9 for (III). In order to explore the role of solute-solvent interactions, all calculations concerning absorption spectra of neutral and protonated molecules were performed in THF. It is important to note here that results of quantumchemical calculations suggest that in THF the very weak long-wavelength transition is overlapped by the red-shifted shorter wavelength transition peak. As a consequence in polar solvents long-wavelength absorption spectrum of molecules under study possesses only one transition (see Fig. 1 and Table 2). Despite the fact that the theoretical calculations suggest only one transition in the long-wavelength
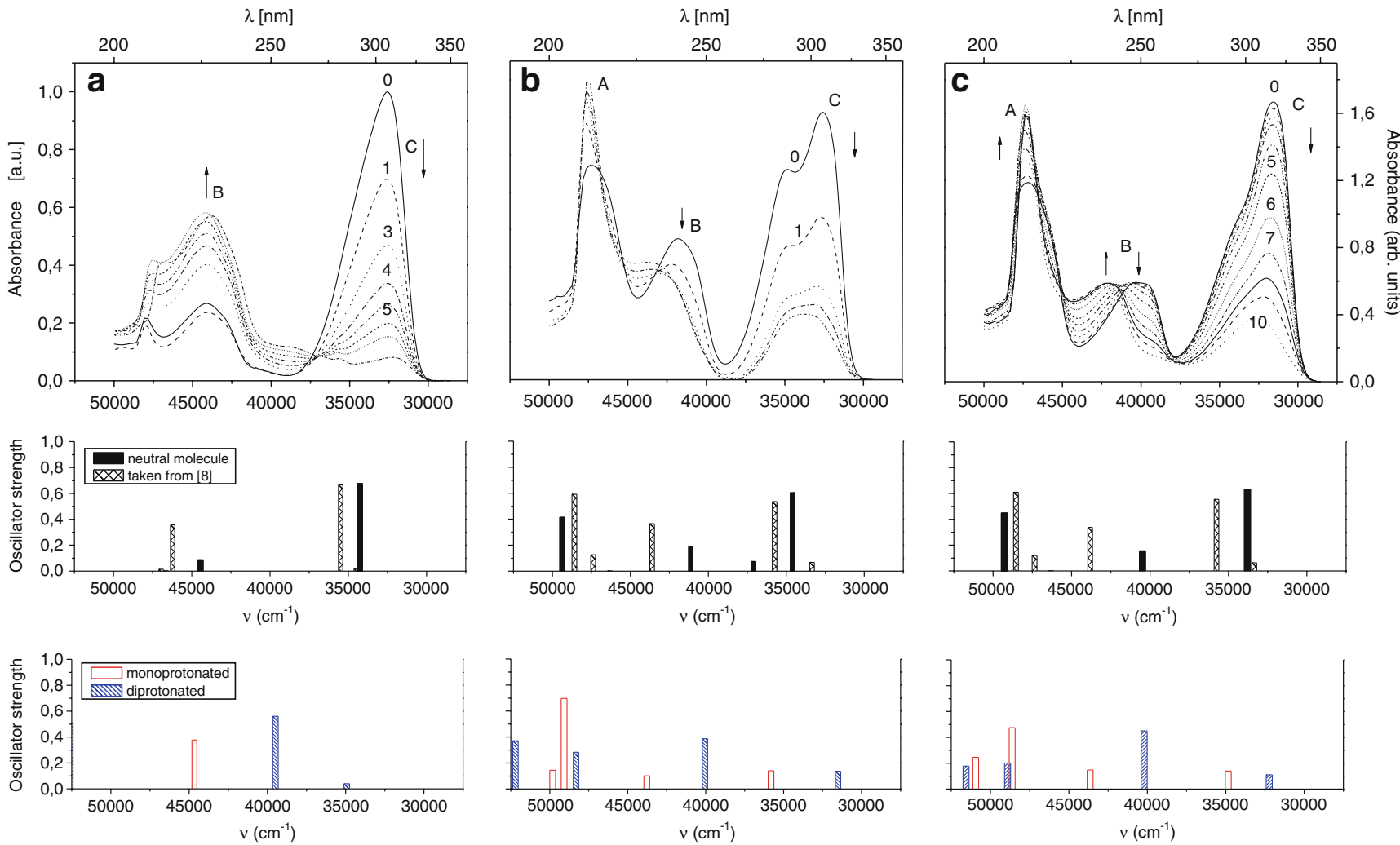

Fig. 1 Absorption spectra of I (a), II (b) and III (c) as a function of the $\mathrm{HCl}$ concentration in THF; 0-neat THF; $1-0.1 \mathrm{M} ; 2-0.2 \mathrm{M}$; 3$0.29 \mathrm{M} ; 4-0.49 \mathrm{M} ; 5-0.98 \mathrm{M} ; 6-1.97 \mathrm{M} ; 7-2.79 \mathrm{M} ; 8-3.6 \mathrm{M} ; 9$ $4.43 \mathrm{M}$ and $10-6.065 \mathrm{M}$. The bars under the absorption curves give the theoretical electronic state energy values and corresponding oscillator strengths of neutral molecules in vapour-phase (taken from [8]) and in THF, and mono- and dicationic forms of the parent molecule in THF 
Table 2 Theoretical values of singlet excited states, $E_{i}$, and corresponding oscillator strengths, $f_{i}$, of molecules under study

\begin{tabular}{|c|c|c|c|}
\hline Compound & Transition state & $E_{i}\left(\mathrm{~cm}^{-1}\right)$ & $f_{i}$ \\
\hline I & $\begin{array}{l}S_{1} \\
S_{2} \\
S_{3} \\
S_{4} \\
S_{5}\end{array}$ & $\begin{array}{r}34267,7 / 34494,7^{\mathrm{a}} \\
/ 35494,3^{\mathrm{a}} \\
44452,3 / 46227,5^{\mathrm{a}} \\
53259,5 / 46639,9^{\mathrm{a}} \\
54185,9 / 46960,2^{\mathrm{a}} \\
\end{array}$ & $\begin{array}{r}0,6764 / 0,0180^{a} \\
/ 0,6659^{a} \\
0,0875 / 0,3572^{a} \\
0,2935 / 0,0022^{a} \\
0,4138 / 0,0147^{a} \\
\end{array}$ \\
\hline IA & $\begin{array}{l}S_{1} \\
S_{2} \\
S_{3} \\
S_{4}\end{array}$ & $\begin{array}{l}44664,8 \\
53050,4 \\
53084,2 \\
54100,8\end{array}$ & $\begin{array}{l}0,3770 \\
0,5279 \\
0,3330 \\
0,2414\end{array}$ \\
\hline IB & $\begin{array}{l}S_{1} \\
S_{2} \\
S_{3}\end{array}$ & $\begin{array}{l}34930,8 \\
39488,2 \\
52590,1\end{array}$ & $\begin{array}{l}0,0401 \\
0,5601 \\
0,5086\end{array}$ \\
\hline II & $\begin{array}{l}S_{1} \\
S_{2} \\
S_{3} \\
S_{4} \\
S_{5}\end{array}$ & $\begin{array}{r}34602,1 / 33355,2^{\mathrm{a}} \\
/ 35750,3^{\mathrm{a}} \\
37105,8 / 43606,7^{\mathrm{a}} \\
41126,9 / 46306,4^{\mathrm{a}} \\
49385,2 / 47387,2^{\mathrm{a}}\end{array}$ & $\begin{array}{r}0,6039 / 0,0680^{\mathrm{a}} \\
/ 0,5355^{\mathrm{a}} \\
0,0747 / 0,3656^{\mathrm{a}} \\
0,1885 / 0,0022^{\mathrm{a}} \\
0,4161 / 0,1262^{\mathrm{a}}\end{array}$ \\
\hline IIA & $\begin{array}{l}S_{1} \\
S_{2} \\
S_{3} \\
S_{4}\end{array}$ & $\begin{array}{l}35805,1 \\
43773,2 \\
49079,8 \\
49810,7\end{array}$ & $\begin{array}{l}0,1399 \\
0,1019 \\
0,6967 \\
0,1442\end{array}$ \\
\hline IIB & $\begin{array}{l}S_{1} \\
S_{2} \\
S_{3} \\
S_{4}\end{array}$ & $\begin{array}{l}31507,0 \\
40048,0 \\
48311,5 \\
52200,2\end{array}$ & $\begin{array}{l}0,1367 \\
0,3873 \\
0,2824 \\
0,3708\end{array}$ \\
\hline III & $\begin{array}{l}S_{1} \\
S_{2} \\
S_{3} \\
S_{4}\end{array}$ & $\begin{array}{r}33784,9 / 33351,2^{\mathrm{a}} \\
/ 35761,1^{\mathrm{a}} \\
40480,9 / 43814,5^{\mathrm{a}} \\
49282,9 / 46304,7^{\mathrm{a}}\end{array}$ & $\begin{array}{r}0,6331 / 0,0632^{\mathrm{a}} \\
/ 0,5549^{\mathrm{a}} \\
0,1553 / 0,3381^{\mathrm{a}} \\
0,4491 / 0,0020^{\mathrm{a}}\end{array}$ \\
\hline IIIA & $\begin{array}{l}S_{1} \\
S_{2} \\
S_{3} \\
S_{4}\end{array}$ & $\begin{array}{l}34845,6 \\
43643,3 \\
48614,5 \\
50939,8\end{array}$ & $\begin{array}{l}0,1387 \\
0,1473 \\
0,4750 \\
0,2457\end{array}$ \\
\hline IIIB & $\begin{array}{l}S_{1} \\
S_{2} \\
S_{3} \\
S_{4}\end{array}$ & $\begin{array}{l}32225,8 \\
40201,0 \\
48911,7 \\
51554,4\end{array}$ & $\begin{array}{l}0,1099 \\
0,4508 \\
0,2007 \\
0,1778\end{array}$ \\
\hline
\end{tabular}

${ }^{\text {a }}$ Theoretical values of singlet excited states, $E_{i}$, and corresponding oscillator strengths, $f_{i}$, of neutral molecules in vapour-phase are taken from [8] 
absorption spectrum in THF solution the long-wavelength band consists of two transitions pictured by Gaussian profiles [7, 8], possessing maxima at $304.9 \mathrm{~nm}$ and $291.3 \mathrm{~nm}$ for I, $309.9 \mathrm{~nm}$ and $288.2 \mathrm{~nm}$ for II and $318.7 \mathrm{~nm}$ and $299.3 \mathrm{~nm}$ for III, respectively. It is important to note here that these two transitions undergo an energy-level reversal of the charge transfer and normal electronic transitions upon the environment change from vapour phase to the solvents [8, 22-24]. This phenomenon (energy-level reversal) has also been observed in the absorption spectrum of p-aminosalicylic acid and methyl p-dimethylaminobenzoate by the change of solvent from non-polar to polar one [22-24]. It must be noted that performed calculations using the Gaussian 09 code within the polarized continuum model of the solvent used do not confirm this phenomenon although the obtained absorption spectra show its existence.

As can be seen in Figs. 1 and 2, the absorption and the fluorescence spectra of molecules under study undergo very complex changes when adding $\mathrm{HCl}$ to the THF solution. The absorption spectra of each compound in acidic THF solutions form isobestic points, i.e., for molecule I only one is located at $\nu=37,500 \mathrm{~cm}^{-1}(266.7 \mathrm{~nm})$, for molecules II and III two points are located at $\nu=42,300 \mathrm{~cm}^{-1}(236.4 \mathrm{~nm})$ and $45,200 \mathrm{~cm}^{-1}(221.2 \mathrm{~nm})$, and at $41,200 \mathrm{~cm}^{-1}$ $(242.7 \mathrm{~nm})$ and $45,000 \mathrm{~cm}^{-1}(222.2 \mathrm{~nm})$, respectively. Noted changes of the absorption spectra suggest that the solute molecules undergo prototropic reactions in the electronic ground, $S_{0}$, and excited, $S_{1}$, states.

As can be seen in Fig. 1, upon increasing the $\mathrm{HCl}$ concentration the intensity of the $\mathrm{C}$ absorption band decreases. In the case of molecule I this behaviour is accompanied by the intensity increase of the $\mathrm{B}$ band. On the other hand, for molecules II and III new bands at $\nu \cong 44,000 \mathrm{~cm}^{-1}(227.3 \mathrm{~nm})$ (molecule II) and $42,500 \mathrm{~cm}^{-1}(235.3 \mathrm{~nm})$ (molecule III) are being created (see Fig. 1). For these molecules a significant increase of the A band intensity, and a decrease of theirs fullwidth at half maximum, $\Delta v_{1 / 2}$, is also noticed.

In order to make the understanding the prototropic reactions appearing in the molecules under study more clear, Table 3 assembles the long-wavelength absorption and LE and ICT fluorescence bands maxima (obtained using a linear combination of Gaussian profiles, it is not shown here) of molecules in acidic solutions of THF. Analysing the assembled spectra in Fig. 1 and data collected in Table 3, we can state that:

i. Addition of $\mathrm{HCl}$ acid to the neat solution generates a $\mathrm{H}^{+}$reaction with the non-bonding electrons of the $\mathrm{NMe}_{2}$ or $-\mathrm{COOMe}(-\mathrm{OAc})$ substituents of the molecules under study. The $\mathrm{H}^{+}$ion forms a chemical bond with the $n$-electrons of $\mathrm{N}$ atom of the dimethylamino substituent or with the -OAc group. In consequence, new cationic functional groups $-\mathrm{NH}^{+} \mathrm{Me}_{2}$ and
Fig. 2 Normalized fluorescence spectra of I (panels I (a) and I (a')), II (panels II (b) and II (b')) and III (panels III (c1), III (c1'), III (c2) and III (c2')) excited at different wavelengths in neat THF and for different concentrations of $\mathrm{HCl}$. The concentration of $\mathrm{HCl}$ is: $0-0 \mathrm{M} ; 1-0.1 \mathrm{M}$; 2-0.2 M; 3-0.29 M; 4-0.49 M; 5-0.98 M; 6-1.97 M; 7-2.79 M; 83.6 M; 9-4.43 M and 10-6.065 M. Arrows indicate the fluorescence intensity changes caused by an increasing $\mathrm{HCl}$ concentration

$\mathrm{COH}^{+} \mathrm{OMe}$ are formed. The $-\mathrm{NH}^{+} \mathrm{Me}_{2}$ group does not conjugate with the benzene skeleton whereas the $\mathrm{COH}^{+} \mathrm{OMe}$ substituent decreases the electron accepting abilities of MB (methyl benzoate) moiety.

ii. The positions of the absorption maxima, $\lambda_{S W}^{G}$ and $\lambda_{L W}^{G}$ (obtained using the Peak Fit program to decompose the long-wavelength $\mathrm{C}$ band into a linear combination of Gaussian functions), do not change when adding $\mathrm{HCl}$ to the THF solution. The noticed differences in the $\lambda_{S W}^{G}$ and $\lambda_{L W}^{G}$ for different $\mathrm{HCl}$ concentrations (see Table 3) lie in the error limit of their experimental and computer fitting program determination.

To test whether the changes in the absorption spectra originate from the mono- and/or dications of the parent molecules, a series of quantum-chemical calculations were carried out. As mentioned earlier, Fig. 1 presents the absorption spectra of molecules under study as a function of the $\mathrm{HCl}$ concentration in THF. Additionally in the lower panels of Fig. 1, the bars under the absorption curves give the theoretical electronic state energy values and corresponding oscillator strengths of the neutral molecules in vapour-phase (taken from [8]) and in THF, and the mono- and dicationic forms of the parent molecule. Table 2 assembles the spectroscopic data (energy values of the $S_{i=1}, \ldots$ states and the associated oscillator strengths) concerning the low-lying states (up to $50,000 \mathrm{~cm}^{-1}$ ) for the neutral molecules and their mono- and dicationic forms. Analyzing the data assembled in Table 2 in connection with the graphical presentation in Fig. 1, it follows that:

i. The absorption spectra of molecules under study in hydrochloric acid solutions consist of electronic transitions of three different luminescent centers, absorbing at different wavelengths (i.e., neutral molecule and its mono- and dicationic forms - their formation are represented by the reactions (1), (1a) and (1b), see Chapter 3.4). Generally, the participation of protonated forms of studied molecules in absorption spectrum is higher for high concentrations of $\mathrm{HCl}$. The absorption of these components contributes more at the shortwavelength at the absorption spectrum for I, whereas in the case of II and III it contributes in the longwavelengths part, also (see Fig. 1 and Table 2).

ii. The intensity of the $\mathrm{C}$ absorption band decreases upon increasing the $\mathrm{HCl}$ concentration. The long-wavelength 

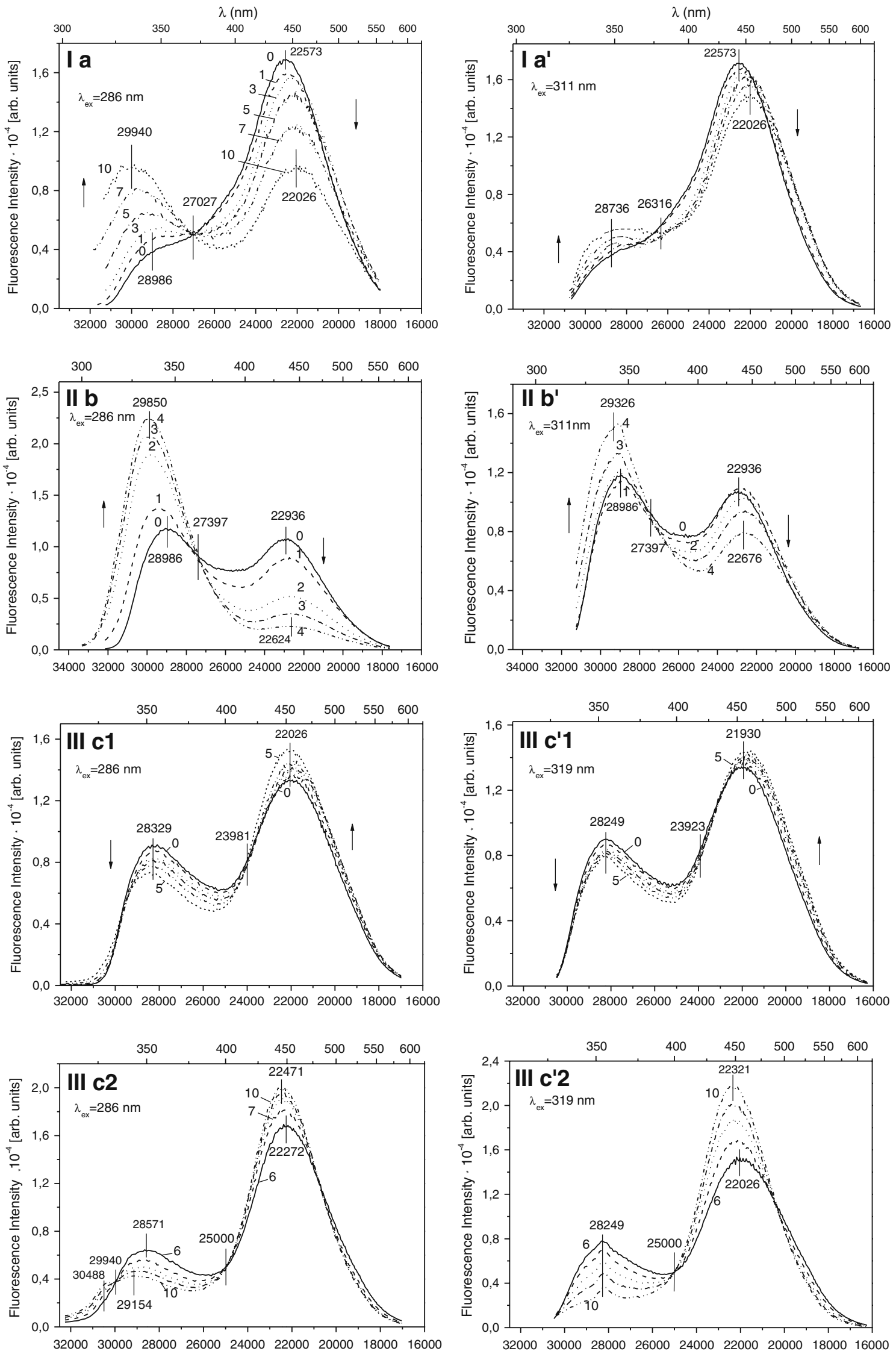

$\mathrm{v}\left(\mathrm{cm}^{-1}\right)$

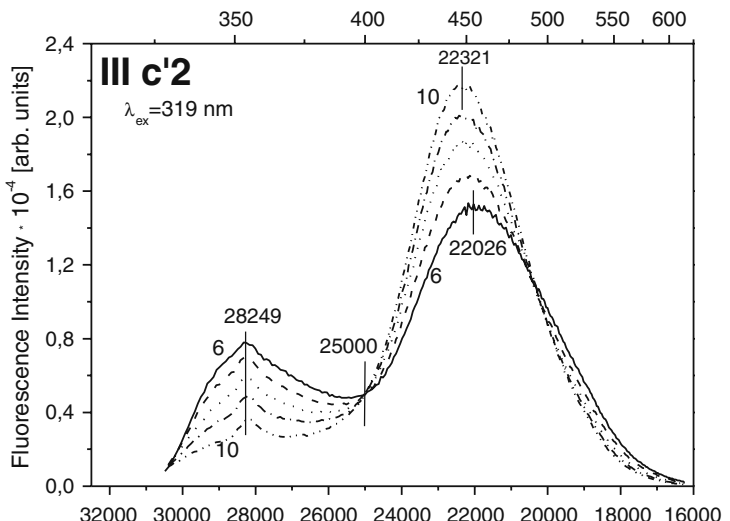

$v\left(\mathrm{~cm}^{-1}\right)$ 
Table 3 The long-wavelength absorption and LE and ICT fluorescence bands maxima (obtained using a linear combination of Gaussian profiles) (in $\mathrm{nm} / \mathrm{cm}^{-1}$ ) of molecules I, II and III in acidic solutions of THF

\begin{tabular}{|c|c|c|c|c|c|}
\hline \multirow[t]{2}{*}{ Molecule } & \multicolumn{2}{|c|}{ Long-wavelength absorption band $\left(\mathrm{nm} / \mathrm{cm}^{-1}\right)$} & \multirow[t]{2}{*}{$\lambda_{\mathrm{ex}}(\mathrm{nm})$} & \multicolumn{2}{|c|}{ Fluorescence band maxima $\left(\mathrm{nm} / \mathrm{cm}^{-1}\right)$} \\
\hline & $\lambda_{S W}^{G \mathrm{a}}$ & $\lambda_{L W}^{G \text { a }}$ & & $\lambda_{\mathrm{F}}(\mathrm{LE})$ & $\lambda_{\mathrm{F}}(\mathrm{ICT})$ \\
\hline \multicolumn{6}{|l|}{ I } \\
\hline \multicolumn{6}{|c|}{$\mathrm{HCl}$ concentration $0 \mathrm{M}$} \\
\hline & 291.3 & 304.9 & $286 / 311$ & 353.9 & 443.8 \\
\hline & 34,329 & 32,798 & & 28,257 & 22,533 \\
\hline \multicolumn{6}{|c|}{$\mathrm{HCl}$ concentration $2.2 \mathrm{M}$} \\
\hline & 284.6 & 308.5 & 286 & 334.8 & 452.4 \\
\hline & 35,133 & 32,420 & & 29,868 & 22,104 \\
\hline & & & 311 & 355.4 & 454.5 \\
\hline & & & & 28,137 & 22,004 \\
\hline \multicolumn{6}{|l|}{ II } \\
\hline \multicolumn{6}{|c|}{$\mathrm{HCl}$ concentration $0 \mathrm{M}$} \\
\hline & 288.2 & 309.9 & $286 / 311$ & 345.0 & 435.7 \\
\hline & 34,698 & 32,362 & & 28,986 & 22,952 \\
\hline \multicolumn{6}{|c|}{$\mathrm{HCl}$ concentration $0.39 \mathrm{M}$} \\
\hline & 286.3 & 304.9 & 286 & 335.5 & 441.9 \\
\hline & 34,928 & 32,798 & & 29,806 & 22,630 \\
\hline & & & 311 & 342.7 & 443.3 \\
\hline & & & & 29,180 & 22,558 \\
\hline \multicolumn{6}{|l|}{ III } \\
\hline \multicolumn{6}{|c|}{$\mathrm{HCl}$ concentration $0 \mathrm{M}$} \\
\hline & 292.4 & 318.7 & $286 / 319$ & 354.6 & 454.5 \\
\hline & 34,203 & 31,377 & & 28,201 & 22,002 \\
\hline \multicolumn{6}{|c|}{$\mathrm{HCl}$ concentration $0.98 \mathrm{M}$} \\
\hline & 291.6 & 317.3 & 286 & 352.0 & 454.7 \\
\hline & 34,290 & 31,520 & & 28,409 & 21,993 \\
\hline & & & 319 & 353.9 & 459.4 \\
\hline & & & & 28,257 & 21,768 \\
\hline \multicolumn{6}{|c|}{$\mathrm{HCl}$ concentration $1.97 \mathrm{M}$} \\
\hline & 291.5 & 317.0 & 286 & 349.7 & 449.6 \\
\hline & 34,300 & 31,550 & & 28,600 & 22,244 \\
\hline & & & 319 & 353.3 & 456.7 \\
\hline & & & & 28,303 & 21,879 \\
\hline \multicolumn{6}{|c|}{$\mathrm{HCl}$ concentration $6.07 \mathrm{M}$} \\
\hline & 290.7 & 311.2 & 286 & 343.2 & 446.8 \\
\hline & 34,400 & 32,135 & & 29,138 & 22,380 \\
\hline & & & 319 & 354.9 & 447.3 \\
\hline & & & & 28,175 & 22,358 \\
\hline
\end{tabular}

\footnotetext{
${ }^{a}$ Determined from the decompositions of the long-wavelength absorption band into two separated Gaussian bands
}

absorption band in the presence of $\mathrm{HCl}$ at its maximum concentration used consists of two overlapping components (mono- and dicationic forms) for II and III, whereas for I, it corresponds to the $S_{0} \rightarrow S_{1}$ transition of the dicationic form of the parent molecule (see Fig. 1 and Table 2). iii. For molecule I, the intensity of the B absorption band increases as the $\mathrm{HCl}$ concentration increases. This behaviour is understandable in terms of the $S_{0} \rightarrow S_{1}$ transition of the monocationic form of molecule I. It is important to note here that the new bands at $\nu \approx$ $40,000 \mathrm{~cm}^{-1}$ (for I), $\nu \approx 44,000 \mathrm{~cm}^{-1}$ (for II), and $\nu \approx$ 
$42,500 \mathrm{~cm}^{-1}$ (for III) correspond to the $S_{0} \rightarrow S_{2}$ transition of the dicationic form of $\mathrm{I}$ and of the monocationic forms of II and III, respectively.

\section{Steady State LE and ICT Fluorescence Spectra Analysis}

As it was shown in the previous section (see also Fig. 1), in acidic solutions a part of neutral solute molecules is excluded from the fluorescence emission as a result of the prototropic reaction. Figure 3 shows exemplary fluorescence spectra of III in neat THF and its hydrochloric acid solutions at different $\mathrm{HCl}$ concentrations. It is seen that the intensity of both (LE and TICT) fluorescence bands decreases with increasing concentration of $\mathrm{HCl}$. To obtain more information about the $\mathrm{HCl}$ concentration effect on the both emission modes of the fluorescence spectrum of molecules under study the analyzed fluorescence spectra are normalized in a way that each of the areas under the fluorescence curves were normalized to unity. In this case, each fluorescence spectrum corresponds to the emission from the same number of emitting solute molecules under study. In the studied concentration range of $\mathrm{HCl}$, the fluorescence spectra consist of two partially overlapping bands, i.e., the short-wavelength (LE) band at about $350 \mathrm{~nm}$ $\left(28,571 \mathrm{~cm}^{-1}\right)$ and the long-wavelength (ICT) band at about $450 \mathrm{~nm}\left(22,222 \mathrm{~cm}^{-1}\right)$. Figure 2 shows that in a neat THF solution the ICT fluorescence band of I, which is assigned to the emission from the non-planar (TICT) form, dominates. In the $0-1.79 \mathrm{M}$ concentration range of $\mathrm{HCl}$ the ratio of nonplanar (TICT) to planar (LE) emitting forms (for $\lambda_{\text {exc }}=$ $286 \mathrm{~nm}$ ) changes from 81 vs. 19 to 63 vs. 37\%, respectively, whereas for $\lambda_{\text {exc }}=311 \mathrm{~nm}$ the ratio shows very week dependence on the $\mathrm{HCl}$ concentration. In the case of molecule II in the neat THF solution (see Fig. 2), the number of both emitting forms is almost equal (52 vs. 48\%). The concentration change of $\mathrm{HCl}$ from 0 to $0.49 \mathrm{M}$ (the reaction of $\mathrm{H}^{+}$ion binding to the $\mathrm{N}$ or $\mathrm{O}$ atom of the $-\mathrm{NMe}_{2}$ or $-\mathrm{OAc}$ substituent, respectively) causes the intensity change of both bands giving the final ratio $11 v s .89 \%$ (for $\lambda_{\mathrm{exc}}=286 \mathrm{~nm}$ ).

In the case of molecule III, (see Fig. 2), the changes of the fluorescence spectra are more complex, i.e., the fluorescence spectrum of III in a mixed solution leads to two isosbestic points, in distinction to one isosbestic point for I and II. The presence of these points indicates a formation of well defined $1: 1$ or $1: 2 \mathrm{H}^{+}$complexes in the emitting ensemble of molecules. The above observation is supported by respective changes in the location of the LE and ICT emission peaks maxima. In the present paper, the fluorescence behaviour of the molecules under study has been studied as a function of the excitation wavelength (i.e. the short-wavelength $\left(\lambda_{\mathrm{exc}}=\right.$ $286 \mathrm{~nm}$ for all studied molecules) and the long-wavelength excitation $\left(\left(\lambda_{\text {exc }}=311 \mathrm{~nm}\right.\right.$ for I, II and $319 \mathrm{~nm}$ for III $\left.)\right)$. It is noteworthy that for higher concentration of $\mathrm{HCl}$, when excitation is carried out at the long-wavelength part of the absorption spectrum mainly neutral form of molecule I is excited, whereas in the case of molecules II and III the mono- and dicationic are excited also (see Fig. 1).

Table 3 assembles the absorption (decomposed into two Gaussian profiles) and emission peak maxima of the neutral and cationic forms of the molecules under study. A scrupulous analysis of the emission spectra determined in neat and mixed solutions (see Fig. 2 and Table 3) allows to state that:

i. When the concentration of $\mathrm{HCl}$ increases from 0 to the maximum concentration used and the excitation wavelength equals $286 \mathrm{~nm}$ the LE fluorescence band of I and II is shifted to the shorter wavelength by about
Fig. 3 Fluorescence spectra of III in neat THF and its hydrochloric acid solutions at different $\mathrm{HCl}$ concentrations. Insert-Stern-Volmer plots of the fluorescence quenching of III in THF using $\mathrm{HCl}$ as a quencher

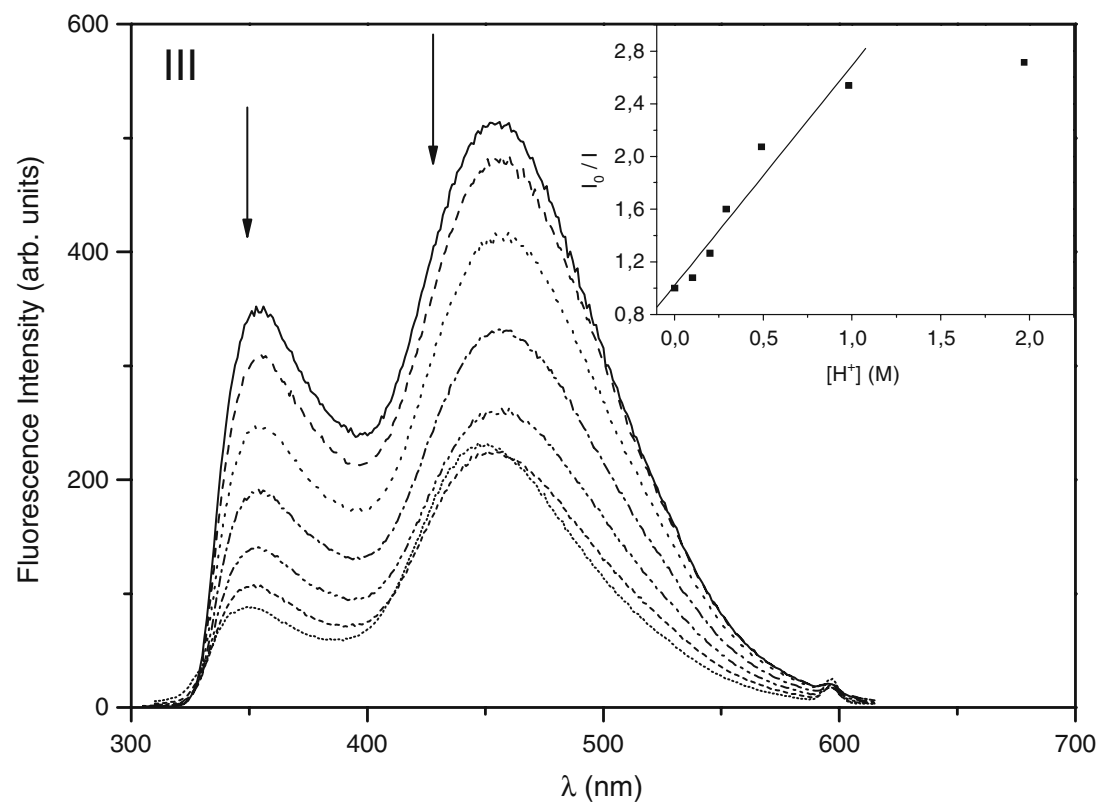


$900 \mathrm{~cm}^{-1}$, whereas the ICT band is shifted to longer wavelength by about $550 \mathrm{~cm}^{-1}$ (I) and $310 \mathrm{~cm}^{-1}$ (II). Upon increasing the concentration of $\mathrm{HCl}$, the intensity of the LE band increases. This behaviour is accompanied by a decrease of the ICT fluorescence band.

ii. The fluorescence spectra of I and II recorded by excitation at $\lambda_{\text {exc }}=311 \mathrm{~nm}$ show the same general dependences as observed for the short-wavelength excitation $\left(\lambda_{\text {exc }}=286 \mathrm{~nm}\right)$.

iii. The fluorescence spectra of III will be discussed for two regions of $\mathrm{HCl}$ concentrations: $0-0.98 \mathrm{M}$ and 1.976.06 M (see Fig. 2). In the first region, the emission spectra of III excited at $286 \mathrm{~nm}$ constitute two distinct isosbestic points at $417 \mathrm{~nm}\left(23,981 \mathrm{~cm}^{-1}\right)$ and $337 \mathrm{~nm}$ $\left(29,674 \mathrm{~cm}^{-1}\right)$. The intensities of both bands change in an opposite direction in comparison to these of molecules I and II, i.e., the intensity of the ICT band increases whereas the LE band decreases by increasing the $\mathrm{HCl}$ concentration. Additionally, a new band located at $\lambda_{\text {max }} \cong 328 \mathrm{~nm}\left(30,488 \mathrm{~cm}^{-1}\right)$ appears-for a low $\mathrm{HCl}$ concentration as a distinct tail and for higher $\mathrm{HCl}$ concentrations as a distinct band (see Fig. 2). It is important to note that for molecule III $\left(\lambda_{\text {exc }}=319 \mathrm{~nm}\right)$ dissolved in acidic solutions in the studied concentration range of $\mathrm{HCl}$ the $\mathrm{LE}$ band position does not change whereas the ICT band is hypsochromically shifted by about $400 \mathrm{~cm}^{-1}$, in comparison to the $\lambda_{\max }$ (ICT) value of III in the neat THF solution. The above findings point that the fluorescence of the two spatial forms (LE and TICT) of studied molecules are quenched by the $\mathrm{H}^{+}$ ions differently. The next sections of this paper are devoted to the above phenomenon.

\section{Static Studies of the $\mathrm{H}^{+}$Reaction in the $S_{0}$ and $S_{1}$ States}

At it was shown earlier the steady-state absorption and emission spectra of the molecules under study in acidic THF solutions undergo complex changes, i.e., the intensity of the long-wavelength absorption band decreases and simultaneously in the UV region a new band is created. Similar changes take place in their fluorescence spectra. The isobestic points noted in the absorption and fluorescence spectra suggest a formation of complexes in the $S_{0}$ and $S_{1}(L E)$ states. We suppose that between the studied molecules and the $\mathrm{H}^{+}$ ion the following reactions can take place:

in the $S_{0}$ state

$$
\begin{aligned}
& \mathrm{MBp}-\mathrm{NMe}_{2}+\mathrm{H}^{+} \stackrel{\mathrm{K}_{\mathrm{g}}^{\prime}}{\longrightarrow} \mathrm{MBp}-\mathrm{NH}^{+} \mathrm{Me}_{2} \\
& \stackrel{K_{g}^{\prime \prime}}{\longrightarrow} \mathrm{MB} \cdots \mathrm{H}^{+} \mathrm{p}-\mathrm{NMe}_{2} \\
& \stackrel{K_{g}^{\prime \prime \prime}}{\longrightarrow} \mathrm{MB} \cdots \mathrm{H}^{+} \mathrm{p}-\mathrm{NH}^{+} \mathrm{Me}_{2}
\end{aligned}
$$

and in the $S_{1}$ state

$$
\begin{aligned}
& \mathrm{MBp}-\mathrm{NMe}_{2}^{*}+\mathrm{H}^{+} \stackrel{\mathrm{K}_{\mathrm{e}}^{\prime}}{\longrightarrow} \mathrm{MBp}-\mathrm{NH}^{+} \mathrm{Me}_{2}^{*} \\
& \rightarrow \mathrm{MBp}-\mathrm{NH}^{+} \mathrm{Me}_{2}+\mathrm{Q}_{1} \\
& \rightarrow \mathrm{MBp}-\mathrm{NH}^{+} \mathrm{Me}_{2}+\mathrm{h} v_{\mathrm{LE}}^{\prime} \\
& \rightarrow \mathrm{MB} \cdots \mathrm{H}^{+} \mathrm{p}-\mathrm{NMe}_{2}+\mathrm{Q}_{2} \\
& \rightarrow \mathrm{MB} \cdots \mathrm{H}^{+} \mathrm{p}-\mathrm{NMe}_{2}+\mathrm{h} v_{\mathrm{ICT}}^{\prime \prime} \\
& \rightarrow \mathrm{MB} \cdots \mathrm{H}^{+} \mathrm{p}-\mathrm{NMe}_{2}+\mathrm{h} v_{\mathrm{LE}}^{\prime \prime} \\
& \rightarrow \mathrm{MB} \cdots \mathrm{H}^{+} \mathrm{p}-\mathrm{NH}^{+} \mathrm{Me}_{2}+\mathrm{NMe}_{2}^{*} v_{\mathrm{LE}}^{\prime \prime \prime} \\
& \stackrel{K_{e}^{\prime \prime \prime}}{\longrightarrow} \mathrm{MB}^{*} \cdot \mathrm{H}^{+} \mathrm{p}-\mathrm{NH}^{+} \mathrm{NMe}_{2}^{*} \\
& \rightarrow \mathrm{H}^{+} \mathrm{p}-\mathrm{NH}^{+} \mathrm{Me}_{2}+\mathrm{Q}_{3}
\end{aligned}
$$

where $\mathrm{Q}_{1}, \mathrm{Q}_{2}$ and $\mathrm{Q}_{3}$ present vibrational energies converted into heat. Naturally, the different luminescent centers (i.e., neutral molecule and its mono- and dicationic forms) absorb at different wavelengths (see Fig. 1). Also, it is important to note that light absorption can promote different luminescent centers (products of reactions (1), (1a), and (1b)).

In the first group of reactions, Eqs. 1, 1b, 2, 2', 2b and 2 'b, the electron donating substituent $\left(-\mathrm{NMe}_{2}\right)$ of methyl benzoate $(\mathrm{MB})$ is replaced by the $-\mathrm{NH}^{+} \mathrm{Me}_{2}$ group, in which the $\mathrm{H}^{+}$ion forms an ionic bond with the non-bonding $n$-electrons of $\mathrm{N}$. The new formed substituent loses the electron donating ability and does not conjugate with the MB skeleton. This mono-cation possesses (as shown in Fig. 1 and Table 2) an absorption spectrum appearing in a different spectral region. Its spectrum is similar to the absorption spectrum of MB and its ortho derivatives [25]. The formed complex, described by reactions (1a) and (2a), (2'a), (2'a), and (2'b) possesses a chemical bond with the OAc group, i.e., $-\mathrm{CO} \cdots \mathrm{H}^{+} \mathrm{OMe}$, which does not influence the conjugation between the benzene skeleton and the acceptor moiety of these molecules. However, it must be added that the bond between benzene and the $\mathrm{CO} \cdots \mathrm{H}^{+} \mathrm{OMe}$ group is weakened causing a blue shift of the long-wavelength Gaussian profile of the absorption band (see Fig. 1 and Table 3). This complex emits LE 
fluorescence quanta, the energies of which differ from those in the neat THF solution by $950 \mathrm{~cm}^{-1}, 860 \mathrm{~cm}^{-1}$ and $2,160 \mathrm{~cm}^{-1}$ for I, II and III, respectively. The efficiency of these reactions depends on the reaction equilibrium constant for each channel. The equilibrium constants for the formation of 1:1 complex in the $S_{0}$ state and in the $S_{1}$ state can be determined from the steady-state spectroscopic measurements using the expression proposed by Benesi and Hildebrand for absorption and fluorescence data [26, 27]:

$\frac{1}{A-A_{0}}=\frac{1}{K_{g}\left(A-A_{0}\right)} \frac{1}{\left[H^{+}\right]}+\frac{1}{A-A_{0}}$

$\frac{1}{I-I_{0}}=\frac{1}{K_{e}\left(I-I_{0}\right)} \frac{1}{\left[H^{+}\right]}+\frac{1}{I-I_{0}}$

where $A_{0}, A$ are the absorbances and $I_{0}, I$ are fluorescence intensities of the neat and acidic solution and $\left[\mathrm{H}^{+}\right]$is the ion concentration. The available absorption and emission spectra do not allow determining the reaction equilibrium constant for each separate reaction channel. Thus the $K_{g}$ and $K_{e}$ values are resultant equilibrium constants of reactions in the ground, $S_{0}$, and excited, $S_{1}$, states, respectively.

Figure $4 \mathrm{a}$ and $\mathrm{b}$ illustrated the double reversal dependence of $1 /\left(A-A_{0}\right)$ vs. $\left[\mathrm{H}^{+}\right]^{-1}$. For each molecule, $A_{0}$ and $A$ are the areas under the absorption profile of the longwavelength band $\int A(\widetilde{v}) d \widetilde{v}$ of the neat and acidic solutions of THF. As it was shown in Fig. 4 the linearity of the plots (Eq. 3) is satisfactory. The correlation coefficient being larger than 0.94 indicates a good linearity. Using the Benesi-Hildebrand equation (Eq. 3) the $K_{g}$ data are determined and their values are assembled in Table 4.

Figure 5 illustrated exemplary straight lines resulting from the linear regression of the LE and ICT fluorescence data fitted to Eq. 4. The correlation coefficient being larger than 0.92 indicates good linearity. Table 4 collects the $K_{e}^{\mathrm{LE}}$ and $K_{e}^{\mathrm{ICT}}$ data determined using the Benesi-Hildebrand procedure. As it was mentioned above the $K_{e}^{\mathrm{LE}}$ and $K_{e}^{\mathrm{ICT}}$ values are resultant equilibrium constants of reactions ( $\left.2^{\prime}\right)$, (2"a), (2'b) and (2'a) initiated by exciting the fluorophore at $\lambda_{S W}^{G}$ and $\lambda_{L W}^{G}$, respectively. Analysing the $K_{g}$ and the $K_{e}^{\mathrm{LE}}$, $K_{e}^{\mathrm{ICT}}$ data, it follows that the equilibrium constants of protopropic reactions in the $S_{0}$ and $S_{1}$ states differ for each molecule under study. The obtained data fulfil the inequalities $K_{g}>K_{e}^{\mathrm{LE}}$ and $K_{g}>K_{e}^{\mathrm{ICT}}$. Also, their values fulfil the following dependencies $K_{g}$ (I) $>K_{g}$ (II) $>K_{g}$ (III) and $K_{e}$ (I) $>K_{e}$ (II) $>K_{e}$ (III), what points that the protopropic reaction of molecules under study is most efficient for molecule I. From Eqs. 2, 2a, and 2b, it follows that these reactions are exothermic, the formed complexes are radiationless and supports fluorescence quenching phenomenon, whereas their emission (see Eqs. 2', 2"a, 2'b and 2'a)
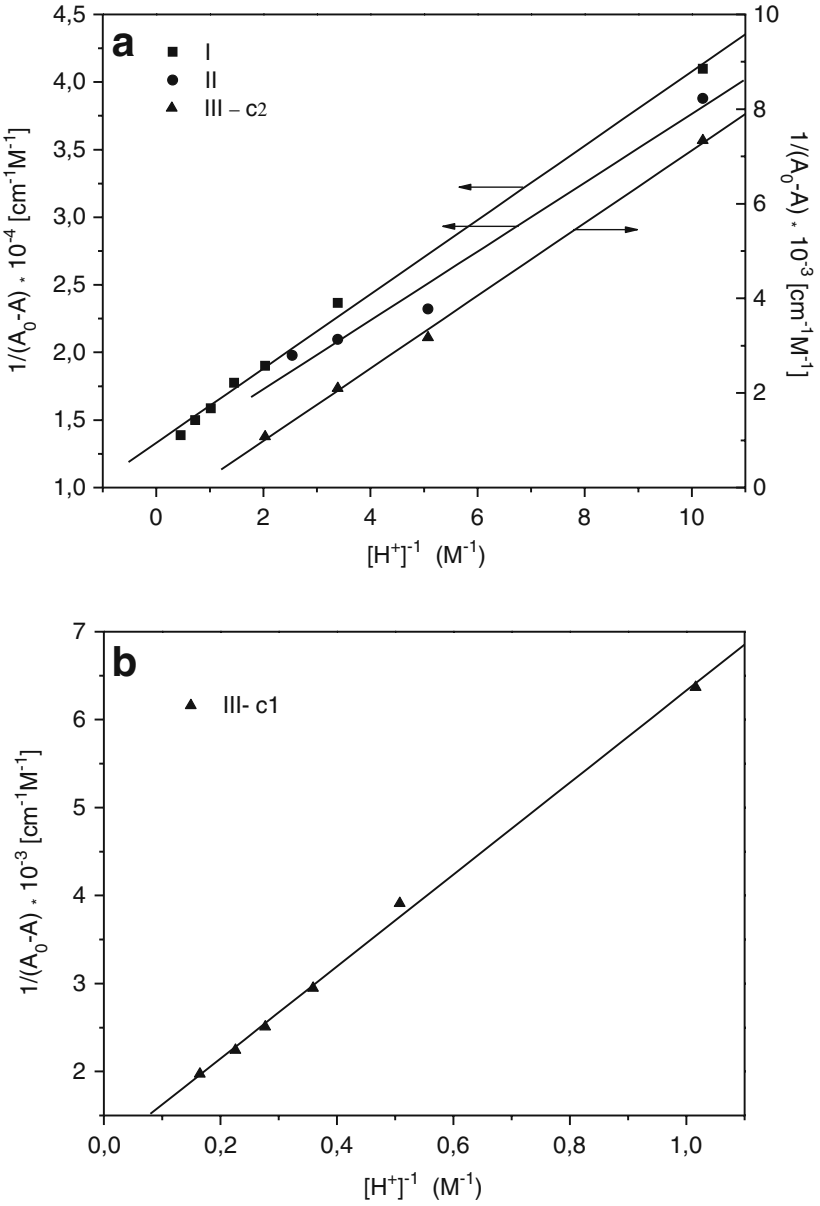

Fig. 4 The Benesi-Hildebrand dependence $\left(1 /\left(\mathrm{A}-\mathrm{A}_{0}\right)\right.$ vs. $\left.\left[\mathrm{H}^{+}\right]^{-1}\right)$ for I, II and III in acidic solutions of THF. c1, c2-low and high concentration range, respectively

supplies quanta at wavelengths that are shorter than those observed for the LE fluorescence band (if the fluorophore is excited at $\lambda_{S W}$ (see Table 3)) or quanta at wavelengths that are longer than those observed for the ICT fluorescence band of the neat solutions (see Figs. 1 and 2).

Analysing the $K_{g}$ and $K_{e}$ data collected in Table 4 in connection with the spectra pictured in Figs. 1, 2 and 3, we can state that:

i. The molecules I, II, and III show different ability to react with the $\mathrm{H}^{+}$ion. The affinities to $\mathrm{H}^{+}$also differ between the $S_{0}, S_{1}(L E)$, and $S_{1}(F C)$ states.

ii. The changes in the absorbances as well as in the LE and ICT fluorecscence band intensities are well described by the respective Benesi-Hildebrand equations.

iii. The $K_{e}^{\mathrm{LE}}$ and $K_{e}^{\mathrm{ICT}}$ values depend on the excitation wavelength.

Analysing the LE and ICT fluorescence intensity changes, it is evident (see Figs. 1, 2 and 3), that the prototropic reactions possess different yields for each molecule. As it was mentioned earlier, Fig. 2 shows the 
Table 4 The equilibrium constants of the $\mathrm{H}^{+}$complex formation in the ground, $K_{g}$, and excited state, $K_{e}$, determined using BenesiHildebrand procedure

\begin{tabular}{|c|c|c|c|c|c|}
\hline \multirow[t]{2}{*}{ Molecule } & \multirow{2}{*}{\multicolumn{2}{|c|}{$K_{g}\left(\mathrm{M}^{-1}\right)$}} & \multirow[t]{2}{*}{$\lambda_{\text {exc }}(\mathrm{nm})$} & \multicolumn{2}{|l|}{$K_{e}\left(\mathrm{M}^{-1}\right)$} \\
\hline & & & & LE band & ICT band \\
\hline \multirow[t]{2}{*}{ I } & \multirow{2}{*}{\multicolumn{2}{|c|}{8.90}} & 286 & 4.74 & 6.67 \\
\hline & & & 311 & 7.78 & 4.72 \\
\hline \multirow[t]{2}{*}{ II } & \multirow{2}{*}{\multicolumn{2}{|c|}{5.37}} & 286 & 2.62 & 2.77 \\
\hline & & & 311 & 0.67 & 0.18 \\
\hline \multirow[t]{2}{*}{ III } & $\mathrm{c1}^{\mathrm{a}}$ & $\mathrm{c} 2^{\mathrm{a}}$ & 286 & 0.51 & 1.10 \\
\hline & 0.48 & 2.92 & 319 & 0.16 & 0.19 \\
\hline
\end{tabular}

${ }^{\mathrm{a}} \mathrm{c} 1$ and $\mathrm{c} 2$ indicate the range of low and high $\mathrm{HCl}$ concentration used

variation of the normalized emission spectra (fluorescence spectrum corresponds to the emission of the same number of emitting molecules) of molecules under study. From Fig. 2, it is evident that in the case of molecules I and II, upon increasing the $\mathrm{H}^{+}$concentration the intensity of the ICT fluorescence band decreases. This behaviour is
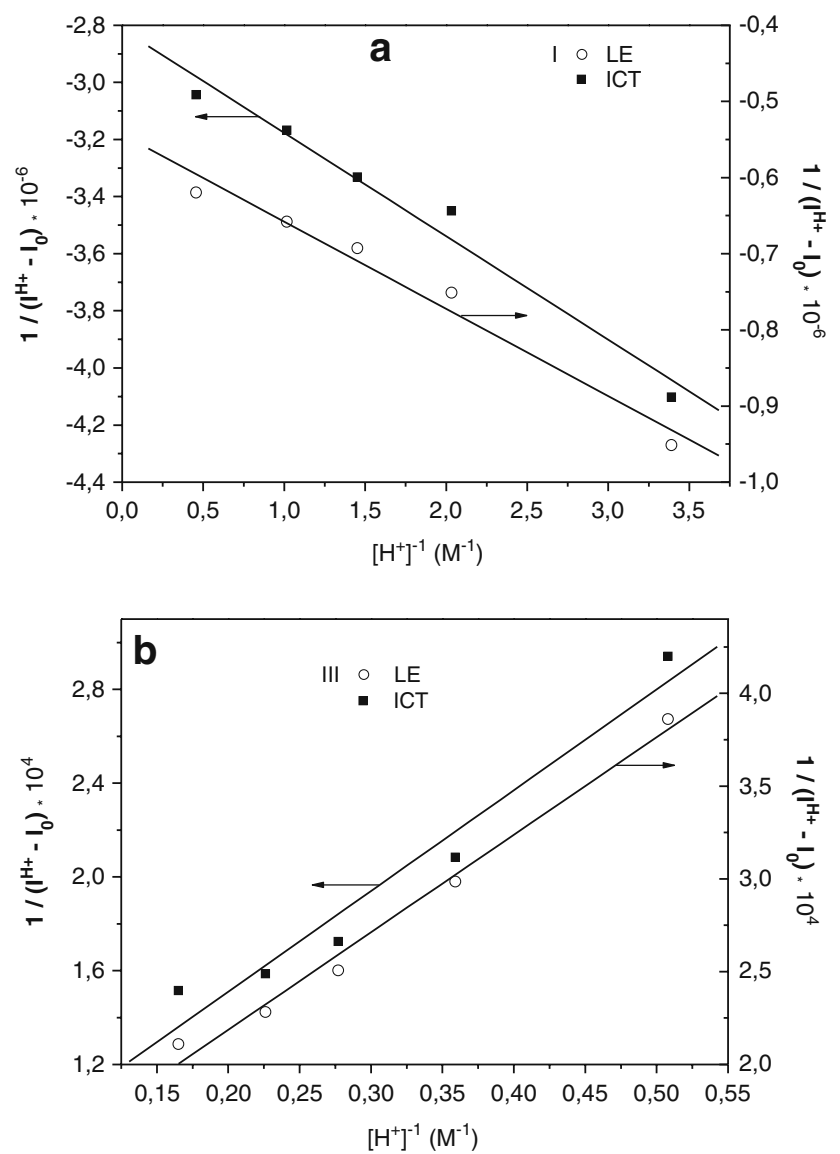

Fig. 5 The Benesi-Hildebrand dependence $\left(1 /\left(I_{L E}^{H^{+}}-I_{L E}\right)\right.$, $1 /\left(I_{I C T}^{H^{+}}-I_{I C T}\right)$ vs. $\left.\left[\mathrm{H}^{+}\right]^{-1}\right)$ for I-panel (a) and III-panel (b) in acidic solutions of THF accompanied by an increase of the LE emission band. Above changes show an apposite direction for molecule III. It is important to note that these fluorescence intensity changes are small in comparison to those noted for I and II.

In is interesting to note that the intensity changes of fluorescence spectra described by the ratio $I_{I C T} / I_{L E}$ or by the
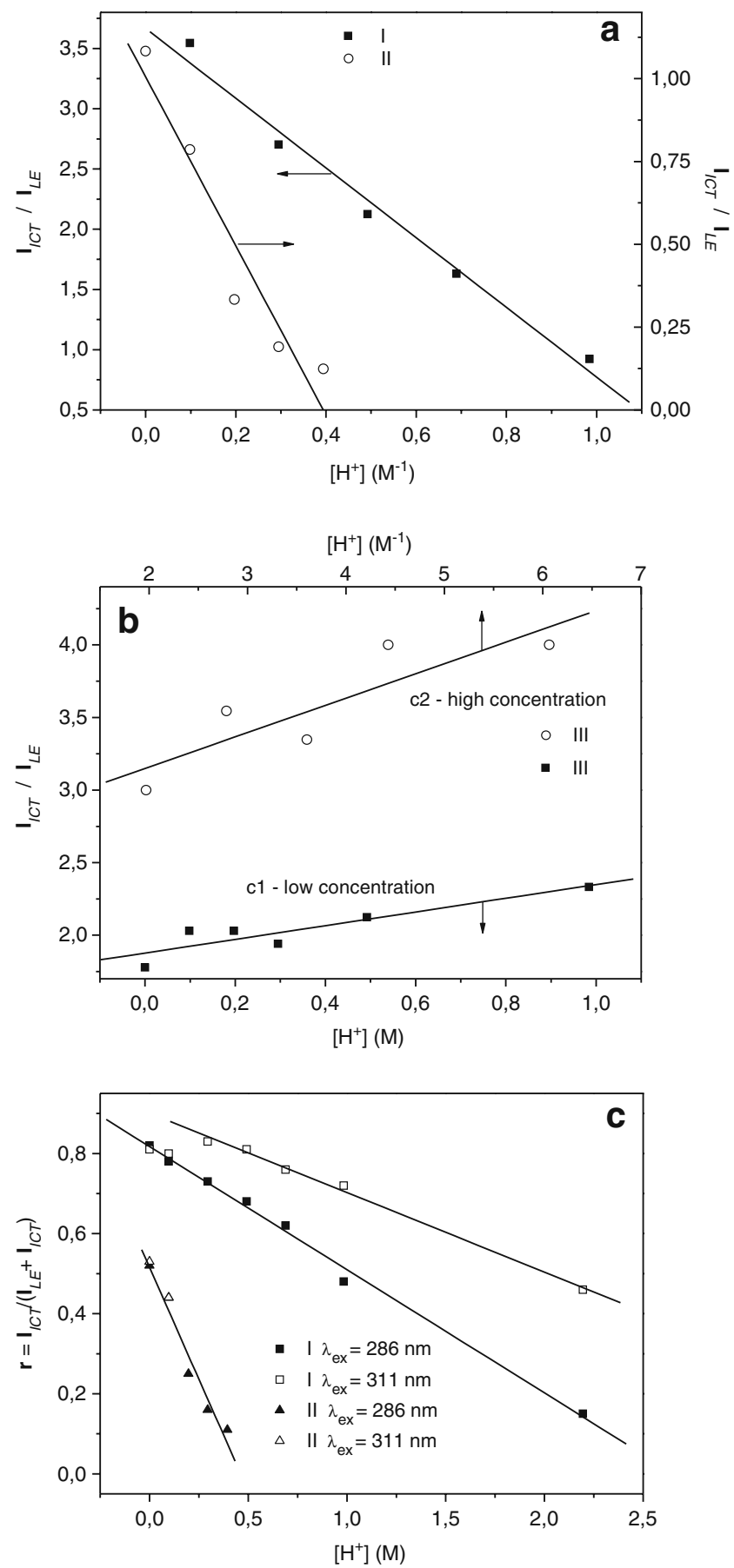

Fig. 6 Fluorescence intensity ratio $\mathrm{I}_{I C T} / \mathrm{I}_{L E}$ vs. $\left[\mathrm{H}^{+}\right]$of I, II and III (panel $\mathbf{a}$ and $\mathbf{b}$ ) and the ICT fluorescence band contribution coefficient, $r=\mathrm{I}_{I C T} /\left(\mathrm{I}_{L E}+\mathrm{I}_{I C T}\right)$ vs. $\left[\mathrm{H}^{+}\right]$(panel c) of I and II determined for two excitation wavelengths 
coefficient of the ICT fluorescence band contribution $r=$ $I_{I C T} /\left(I_{I C T}+I_{L E}\right)$ show a linear dependence on the $\mathrm{H}^{+}$ concentration (see Fig. 6). The correlation coefficient being larger than 0.94 indicates a good linearity. As can be seen in Fig. 6 the fluorescence intensity ratio $I_{L E} / I_{I C T}$ as well as $\boldsymbol{r}$ data are very sensitive to $\mathrm{H}^{+}$concentration for I and II. These findings predestine molecules I and II to be used as acid fluorescence probes in a region of $0-2.5 \mathrm{M}$. For III these intensity changes are small, are in the error limit of their determination.

Fluorescence Quenching Caused by Photoinduced Reaction of $\mathrm{H}^{+}$

Figure 3 shows the fluorescence spectra of III obtained in THF, in the presence of the $\mathrm{HCl}$ at its various concentrations as an example. The spectra have been obtained at fixed solute concentration $\left(\mathrm{c}=10^{-4} \mathrm{M}\right)$ and for the $\mathrm{HCl}$, which concentration changes from 0 to $1.97 \mathrm{M}$. As can be seen in Fig. 3, the increase of $\mathrm{HCl}$ concentration results in a strong decrease of the short- (LE) and long-wavelength (TICT) fluorescence bands. It is important to note here that the intensity of both fluorescence modes decreases with increasing concentration of $\mathrm{HCl}$ for the all studied molecules (dependence for I and II is not shown here).

It is well known that for ideal bimolecular quenching process, the Stern-Volmer equations can be applied [28, 29]:

$I_{F}^{0} / I_{F}=1+k_{q} \tau_{F}^{0}[Q]=1+K_{S V}[Q]$,

and

$\tau_{F}^{0} / \tau_{F}=1+k_{q} \tau_{F}^{0}[Q]=1+K_{S V}[Q]$,

where $k_{q}$ is the bimolecular quenching constant, $I_{F}^{0}$ and $\tau_{F}^{0}$ are the fluorescence intensity and lifetime in the absence of quencher. $I_{F}$ and $\tau_{F}$ are the equivalent parameters in presence of the quencher at a concentration [Q]. If only dynamic quenching is operative without any static quenching, the $K_{S V}$ values obtained from Eqs. 2 and 3 should be identical $[28,29]$.

The insert in Fig. 3 shows straight line from the plot of the $I_{0} / I$ versus $\mathrm{HCl}$ concentration only at low quencher concentrations. Similar behavior is observed for I and II. Taking this into account, it can be concluded that the fluorescence quenching of the molecule under study in acidic THF solutions is very complex and a simple bimolecular process of the Stern-Volmer type is not sufficient to describe the noted changes in the fluorescence intensities.

Concluding the above findings, it must be stated that in a hydrochloric acid solution the studied molecules exist as a mixture of neutral, mono-, and dicationic forms. The reaction of $\mathrm{H}^{+}$with the neutral excited molecules under study creates emissive and/or non-emissive complexes. They arise in a reaction of $\mathrm{H}^{+}$with the $-\mathrm{OAc}$ or/and $-\mathrm{NMe}_{2}$ substituents creating mono- or/and dications of the parent molecule. Naturally, the neutral, mono-, and dicationic forms of the molecules under study possess own characteristic absorption and fluorescence spectra. Their characteristics need further detailed study using time-resolved measurements.

Open Access This article is distributed under the terms of the Creative Commons Attribution Noncommercial License which permits any noncommercial use, distribution, and reproduction in any medium, provided the original author(s) and source are credited.

\section{References}

1. Gormin D, Kasha M (1988) Chem Phys Lett 153:574

2. Gormin D, Heldt J, Kasha M (1989) Chem Phys 136:321

3. Gormin D (1989) J Phys Chem 93:5979

4. Heldt JR, Gormin D, Kubicki A, Heldt J (1997) Słup Prace MatPrzyr 11a:3

5. Aleksiejew M, Heldt JR (2007) J Lumin 126:665

6. Aleksiejew M, Józefowicz M, Heldt JR (2005) Z Naturforsch 60a:655

7. Aleksiejew M, Heldt J, Heldt JR (2008) J Lumin 128:1307

8. Aleksiejew M, Heldt J, Heldt JR (2009) J Lumin 129:208

9. Aleksiejew M (2008) Ph.D. dissertation, University of Gdańsk

10. Krishnamvorthy G, Dogra S (2000) J Phys Chem A 104:2542

11. Ghosh S, Chakraborty A, Kar S, Guchhait N (2009) J Lumin 129:482

12. Angulo G, Grampp G, Rosspeintner A (2006) Spectrochim Acta A $65: 727$

13. Frisch MJ, Trucks GW, Schlegel HB, Scuseria GE, Robb MA, Cheeseman JR, Scalmani G, Barone V, Mennucci B, Petersson GA, Nakatsuji H, Caricato M, Li X, Hratchian HP, Izmaylov AF, Bloino J, Zheng G, Sonnenberg JL, Hada M, Ehara M, Toyota K, Fukuda R, Hasegawa J, Ishida M, Nakajima T, Honda Y, Kitao O, Nakai H, Vreven T, Montgomery JA Jr, Peralta JE, Ogliaro F, Bearpark M, Heyd JJ, Brothers E, Kudin KN, Staroverov VN, Kobayashi R, Normand J, Raghavachari K, Rendell A, Burant JC, Iyengar SS, Tomasi J, Cossi M, Rega N, Millam JM, Klene M, Knox JE, Cross JB, Bakken V, Adamo C, Jaramillo J, Gomperts R, Stratmann RE, Yazyev O, Austin AJ, Cammi R, Pomelli C, Ochterski JW, Martin RL, Morokuma K, Zakrzewski VG, Voth GA, Salvador P, Dannenberg JJ, Dapprich S, Daniels AD, Farkas Ö, Foresman JB, Ortiz JV, Cioslowski J, Fox DJ (2009) Gaussian 09 , revision A1. Gaussian, Inc., Wallingford

14. SSC: a tool for constructing libraries for systematic screening of conformers, available at http://sscf.sf.net

15. Ling S, Gutowski M (2011) J Comp Chem (under review)

16. Lee C, Yang W, Parr RG (1988) Phys Rev B 37:785

17. Stephens PJ, Devlin FJ, Chabalowski CF, Frisch MJ (1994) J Phys Chem 98:1623

18. Hehre WJ, Ditchfield R, Pople JA (1972) J Chem Phys $56: 2257$

19. Krishnan R, Binkley JS, Seeger R, Pople JA (1980) J Chem Phys $72: 50$

20. Barone V, Cossi M, Tomasi J (1997) J Chem Phys 107:3210

21. Stratmann RE, Scuseria GE, Frisch MJ (1998) J Chem Phys 109:8218

22. Shabestary N, El-Bayoumi MA (1984) Chem Phys Lett 106:107 
23. Steward JJP (1983) J Com Chem 10:209

24. Parusel ABJ, Köhler G, Grimme S (1998) J Phys Chem A 102:6297

25. Sinha HK, Muralidharan SM, Yates K (1992) Can J Chem 70:1932

26. Benesi HA, Hildebrand JH (1949) J Am Chem Soc 71:2703
27. Lin L-R, Yang W-L, Zheng G-L, Tiang Y-B (2004) Spectrochim Acta A 60:2209

28. Valeur B (2002) Molecular fluorescence: principles and applications, chap 4. Wiley-VCH, Weinheim

29. Lakowicz JR (2006) Principles of fluorescence spectroscopy. Kluwer Academic/Plenum Publishing Corporation, New York 